\title{
Significance of serum albumin and derived neutrophil-to-lymphocyte ratio score in assessment of disease activity in rheumatoid arthritis patients
}

\author{
Sahar Ganeb, Sami Egaila, Asmaa Hamed and Waleed Hassan * (1)
}

\begin{abstract}
Background: Albumin and derived neutrophil to lymphocyte ratio (dNLR) are known biomarkers that can reflect systemic inflammation and it has been hypothesized that combination of both markers in one score (albumin-dNLR score) can be useful in monitoring rheumatoid arthritis (RA) patients. The current study intended to measure albumin -dNLR score in patients with RA in the order to find whether these new biomarkers could reflect the activity of the disease and the articular activity detected by ultrasonography. We measured serum albumin and dNLR in blood samples obtained from 100 RA patients and from 100 apparently healthy controls (HC). Albumin $-d N L R$ score was calculated according to the presence of hypoalbuminemia $(\leq 3.76 \mathrm{gm} / \mathrm{dl})$ and/or raised dNLR $(>1.37)$.
\end{abstract}

Results: RA patients had a significantly elevated $d N L R(p<0.001)$ and albumin-dNLR score $(p<0.001)$ compared to their levels in $\mathrm{HC}$, while serum albumin was significantly decreased $(p<0.001)$ in RA patients than its level in HC. In RA patients, albumin-dNLR score correlated significantly with DAS28 ( $p<0.001)$, erythrocyte sedimentation rate (ESR) $(p<0.001)$, C-reactive protein $(p<0.001)$, grey scale $(p<0.001)$, power Doppler $(p<0.001)$ and total ultrasound score $(p<0.001)$. Also, tender joint count, ESR and albumin-dNLR score were significant predictors of DAS28 in multivariate regression analysis.

Conclusions: Our study settled that albumin - dNLR score is increased in RA patients than in healthy subjects. The score correlated well with DAS28, acute phase reactants, and ultrasonographic synovitis scores implying that it could be an easy valuable biomarker to monitor RA disease activity.

\section{Background}

Rheumatoid arthritis (RA) is a chronic illness of inflammatory nature that is known to have a prediction to synovial joints [1]. The target of RA management is to reach remission or even low activity state which has been found to improve outcome and reduce joint destruction and subsequent deformities [2].

Recently, monitoring of ongoing activity of RA has been focused on, and many laboratory markers and

\footnotetext{
* Correspondence: Walid.hassan@fmed.bu.edu.eg

Rheumatology, Rehabilitation, and Physical Medicine Department, Faculty of Medicine, Benha University, Farid Nada St, Benha 13518, Egypt
}

radiological modalities including musculoskeletal ultrasound (MSUS) were tested for their validity in measuring and quantifying inflammation in RA patients [3-5].

Albumin synthesis by the liver can be downregulated as a response to malnutrition and intense inflammation, and both mechanisms have been identified in active RA patients [6, 7]. Besides regulation of blood oncotic pressure, albumin has been known as a potent anti-oxidant and a key player in immune-regulatory mechanisms [8].

Also, derived neutrophil-to-lymphocyte ratio (dNLR) is a cytological indicator that reflects the intensity of the inflammatory process in various systemic diseases such

\section{Springer Open}

(๑) The Author(s). 2020 Open Access This article is licensed under a Creative Commons Attribution 4.0 International License, which permits use, sharing, adaptation, distribution and reproduction in any medium or format, as long as you give appropriate credit to the original author(s) and the source, provide a link to the Creative Commons licence, and indicate if changes were made. The images or other third party material in this article are included in the article's Creative Commons licence, unless indicated otherwise in a credit line to the material. If material is not included in the article's Creative Commons licence and your intended use is not permitted by statutory regulation or exceeds the permitted use, you will need to obtain permission directly from the copyright holder. To view a copy of this licence, visit http://creativecommons.org/licenses/by/4.0/. 
as sepsis [9], malignancy [10], multiple sclerosis [11], RA [12], and systemic vasculitis [13]. Chen et al. [14]suggested that combination of albumin and dNLR in one measurement (albumin-dNLR score) can be a simple non- invasive marker that reflects both of disease activity and nutritional status in RA patients.

We aimed to measure albumin-dNLR score in RA and to investigate its possible relation with several clinical, laboratory, and MSUS disease activity parameters.

\section{Methods}

\section{Study participants}

The local ethics committee approved this case-control study on 18 September 2019, and a written consent was provided by all study participants. One hundred RA patients, fulfilling the 2010 (American college of rheumatology/European league against rheumatism) classification criteria [15], were recruited from the Rheumatology and Rehabilitation department, Benha university hospitals. Also, One hundred age and sex comparable apparently healthy subjects were enrolled as a control group. RA patients were subjected to detailed musculoskeletal and systemic evaluation, and the 28 joint score (DAS28) [16] was used to assess disease activity. Patients were excluded if they had conditions that may have direct impact on albumin or dNLR levels as malignancy, other auto-immune disease, recent infection, cardiovascular, hepatic, or renal co-morbidity.

\section{Laboratory investigations}

Venous blood samples were taken for measurement of complete blood count (CBC), erythrocyte sedimentation rate (ESR), $C$ reactive protein (CRP), liver, and kidney function tests. Also, rheumatoid factor (RF) was determined with latex agglutination test, and anti-cyclic citrullinated peptide (anti-CCP) antibodies were assessed using enzyme linked immunosorbent assay (ELISA) method. Serum albumin was assessed by colorimetric method (BioSystems, Barcelona, Spain), CBC was measured using Sysmex-XP300, and dNLR was calculated according to the following equation: neutrophil count/(leukocyte-neutrophil count) [10]. AlbumindNLR score was estimated according to the principle of Chen et al. [14]: score 2 was considered if the patient had both hypoalbuminemia $(\leq 3.76 \mathrm{gm} / \mathrm{dl})$ and raised dNLR (> 1.37); score 1 was considered if the patient had only one abnormality, while score 0 was given for those who did not have neither raised dNLR nor hypoalbuminemia.

\section{Musculoskeletal ultrasound (MSUS) examination}

Assessment of synovitis was preformed using both greyscale (GS) and power Doppler (PD) techniques using 4-point scale. Twelve joints were examined according to the method of Naredo et al. [17]with bilateral scanning of 2nd and 3rd metacarpophalangeal (MCP) joints, wrists, elbows, knees, and ankles. Total score was calculated by summation of both GS and PD scores (Fig. 1). MSUS examination was carried out using Logiq P9 scanner (General Electric, Wisconsin, USA).

\section{Statistical analysis}

Data analysis was executed using V23 of SPSS program (Spss Inc, Chicago, USA). Mean and standard deviation (SD) were used to present normally distributed data, while median and interquartile range (IQR, between 1st and 3rd quartiles) were used for non-parametric data. Two groups in comparison between normally distributed data were done by $t$ test while Mann-Whitney test was performed for non-parametric data.

Various correlations between albumin-dNLR score, dNLR and serum albumin levels, and studied parameters were tested by the Spearman correlation coefficient (rho). The sensitivity and specificity at best cutoff point for prediction of DAS28-ESR were tested by receiver operating characteristic (ROC) curve analysis. Stepwise logistic regression analyses for the factors predicting DAS28 ( $\geq 3.2$ vs $<3.2)$ were conducted, and the results

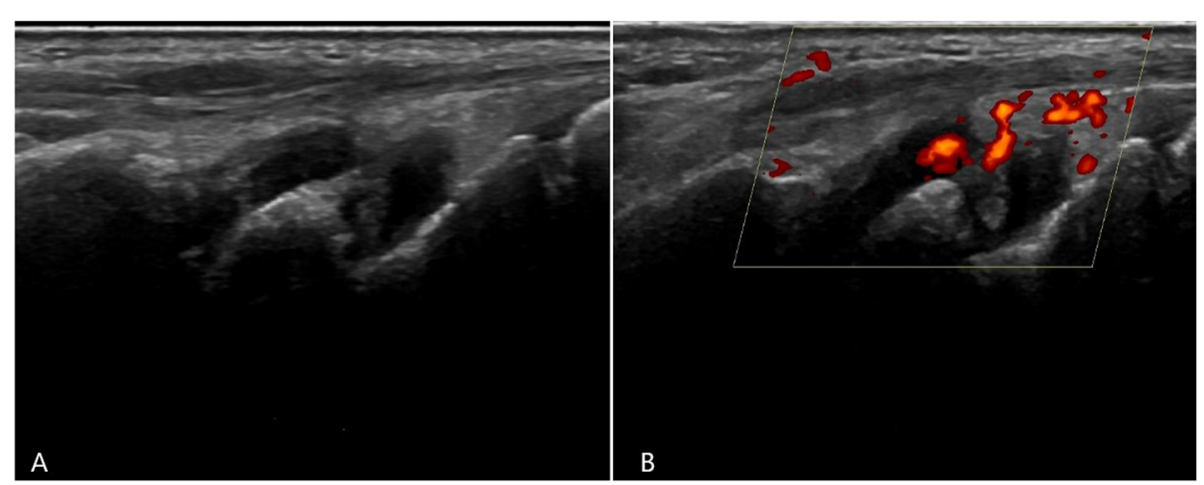

Fig. 1 Active synovitis in greyscale (a) and power Doppler (b) MSUS in 50 years old rheumatoid arthritis patient with increased albumin-dNLR score. MSUS, musculoskeletal ultrasound; dNLR, derived neutrophil-to-lymphocyte ratio 
Table 1 Baseline characteristics of rheumatoid arthritis (RA) patients and the controls

\begin{tabular}{|c|c|c|c|c|c|}
\hline & Variable & & RA patients $(n=100)$ & Controls $(n=100)$ & $P$ value \\
\hline \multirow[t]{3}{*}{ Demographic } & Age (Years) & Mean $\pm S D$ & $43 \pm 10.3$ & $40.5 \pm 11.2$ & 0.1 \\
\hline & Sex & (Male:female) & $(27: 73)$ & $(28: 72)$ & 0.87 \\
\hline & Body mass index $\left(\mathrm{kg} / \mathrm{m}^{2}\right)$ & Mean \pm SD & $27.03 \pm 2.95$ & $26.83 \pm 3.02$ & 0.62 \\
\hline \multirow[t]{7}{*}{ Clinical } & Disease duration (years) & Median (IQR) & $6(3-10.5)$ & - & - \\
\hline & Morning stiffness duration (min) & Median (IQR) & $25(15-30)$ & - & - \\
\hline & Tender joint count & Median (IQR) & $4(2-9)$ & - & - \\
\hline & Swollen joint count & Median (IQR) & $1(0-3)$ & - & - \\
\hline & Cutaneous manifestations & $n(\%)$ & $22(22 \%)$ & - & - \\
\hline & Pulmonary involvement & $n(\%)$ & $18(18 \%)$ & - & - \\
\hline & Ocular involvement & $n(\%)$ & $13(13 \%)$ & - & - \\
\hline \multirow[t]{12}{*}{ Laboratory } & ESR (mm/1st h) & Median (IQR) & $25.5(15-35)$ & - & - \\
\hline & C-reactive protein (mg/l) & Median (IQR) & $8(3.35-16)$ & - & - \\
\hline & Hemoglobin (g/dL) & Mean \pm SD & $11.2 \pm 1.71$ & $13.72 \pm 1.52$ & $<0.001$ \\
\hline & White blood cells $\left(\times 10^{3} / u^{3}\right)$ & Mean \pm SD & $7.47 \pm 1.98$ & $7.34 \pm 1.53$ & 0.01 \\
\hline & Neutrophils $\left(\times 10^{3} /\left.u\right|^{3}\right)$ & Mean \pm SD & $4.46 \pm 1.41$ & $3.96 \pm 0.98$ & $<0.001$ \\
\hline & $d N L R$ & Median (IQR) & $1.5(1.175-1.885)$ & $1.12(0.985-1.33)$ & $<0.001$ \\
\hline & Platelets $\left(\times 10^{3} / \mathrm{ul}^{3}\right)$ & Mean \pm SD & $280.4 \pm 97.25$ & $270.01 \pm 81.61$ & 0.41 \\
\hline & Rheumatoid factor (IU/mL) & Median (IQR) & $32(24-74)$ & - & - \\
\hline & Anti-CCP (IU/mL) & Median (IQR) & $76(31-153)$ & - & - \\
\hline & Albumin (g/dL) & Median (IQR) & $3.9(3.5-4.35)$ & $4.22(3.91-4.73)$ & $<0.001$ \\
\hline & Albumin-dNLR score & Median (Range) & $1(0-2)$ & $0(0-2)$ & $<0.001$ \\
\hline & DAS28-ESR & Median (IQR) & $3.8(2.8-4.42)$ & - & - \\
\hline \multirow[t]{3}{*}{ MSUS } & Greyscale & Median (IQR) & $6(2-11.5)$ & - & - \\
\hline & Power Doppler & Median (IQR) & $1(0-3)$ & - & - \\
\hline & Total 12 joints US score & Median (IQR) & $6.5(2-14.5)$ & - & - \\
\hline \multirow[t]{7}{*}{ Medications } & NSAIDs & $n(\%)$ & $42(42 \%)$ & - & - \\
\hline & Corticosteroids & $n(\%)$ & $58(58 \%)$ & - & - \\
\hline & Hydroxychloroquine & $n(\%)$ & 89 (89\%) & - & - \\
\hline & Methotrexate & $n(\%)$ & 74 (74\%) & - & - \\
\hline & Leflunomide & $n(\%)$ & $31(31 \%)$ & - & - \\
\hline & Sulfasalazine & $n(\%)$ & $11(11 \%)$ & - & - \\
\hline & Biological agents & $n(\%)$ & $16(16 \%)$ & - & - \\
\hline
\end{tabular}

ESR erythrocyte sedimentation rate, $d N L R$ derived neutrophil-to-lymphocyte ratio, Anti-CCP anti-cyclic citrullinated peptide, DAS disease activity score, MSUS musculoskeletal ultrasound, NSAIDs nonsteroidal anti-inflammatory drugs. Bold values refers to significance at $p<0.05$.

were represented as odd ratio (OR) and 95\% confidence interval $(95 \% \mathrm{CI})$. Significant value was considered if $p<$ 0.05 .

\section{Results}

One hundred RA patients with a mean age of $43 \pm 10.3$ years (73 females:27 males) as well as one hundred apparently healthy controls of comparable age and sex were incorporated in our study. Cutaneous involvement was found in $22 \%$ of RA patients in the form of subcutaneous nodules and skin ulcers, while pulmonary involvement was present in $18 \%$ of them and included pleurisy, pleural effusion, and interstitial lung disease. Also, $13 \%$ of our patients had ocular affection in the form of Keratoconjunctivitis sicca, peripheral ulcerative keratitis, and scleritis.

RA patients had a significantly increased dNLR (median $1.5 ; 1.175-1.885 ; p<0.001)$ and albumin-dNLR score (median $1 ; 0-2 ; p<0.001$ ) in comparison with their levels in healthy subjects, while serum albumin was significantly lower (median $3.9 ; 3.5-4.35 ; p<0.001$ ) in RA patients than its level in healthy subjects. The 

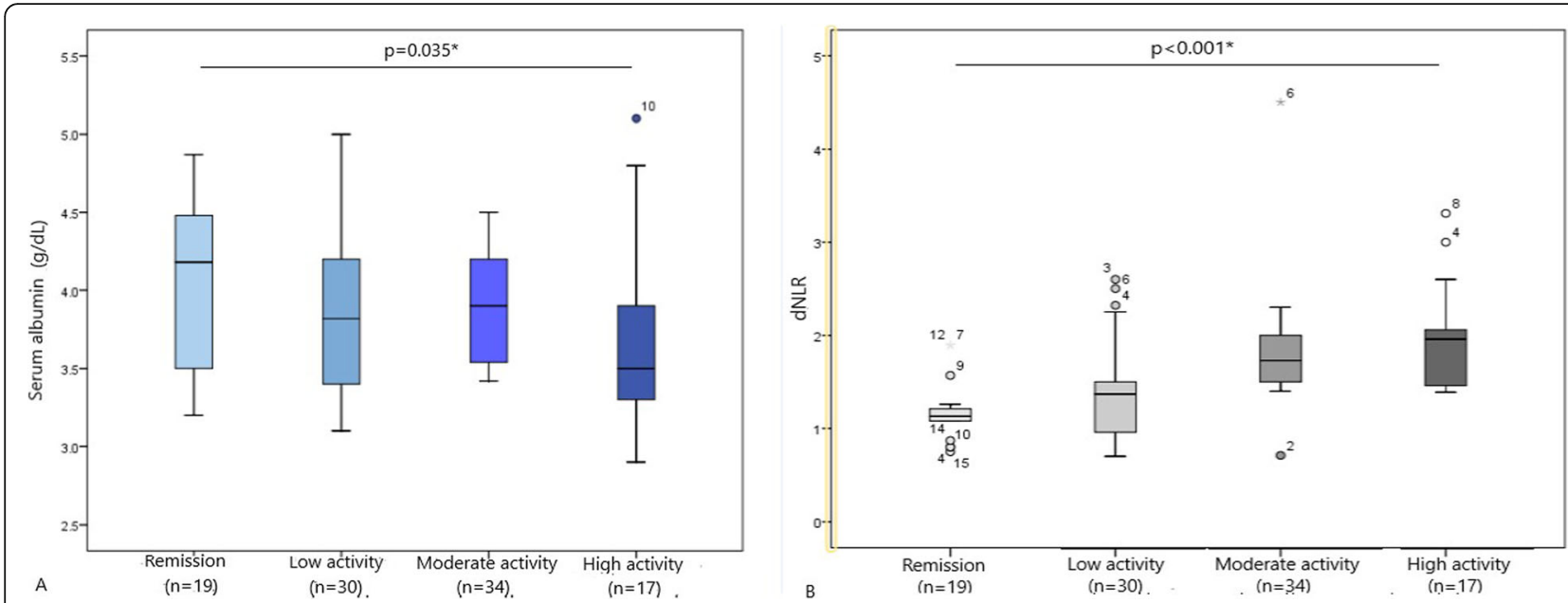

Fig. 2 Comparison of serum albumin levels (a) and dNLR (b) according to different disease activity grades as assessed by DAS28 in rheumatoid arthritis patients. dNLR, derived neutrophil-to-lymphocyte ratio; DAS, disease activity score. ${ }^{*}$ significant at $p<0.05$

Table 2 Correlations between serum albumin, dNLR and albumin-dNLR score with different variables in rheumatoid arthritis patients

\begin{tabular}{|c|c|c|c|c|c|c|}
\hline \multirow[t]{2}{*}{ Variable } & \multicolumn{2}{|l|}{ Albumin } & \multicolumn{2}{|l|}{$\mathrm{dNLR}$} & \multicolumn{2}{|c|}{ Albumin-dNLR score } \\
\hline & $r$ & $p$ & $r$ & $p$ & $\bar{r}$ & $p$ \\
\hline Age (years) & -0.14 & 0.16 & 0.06 & 0.54 & 0.08 & 0.43 \\
\hline Body mass index $\left(\mathrm{kg} / \mathrm{m}^{2}\right)$ & 0.17 & 0.09 & 0.04 & 0.69 & 0.02 & 0.87 \\
\hline Disease duration (years) & -0.09 & 0.37 & 0.12 & 0.23 & 0.17 & 0.09 \\
\hline Morning stiffness (min) & -0.23 & 0.02 & 0.49 & $<0.001$ & 0.44 & $<0.001$ \\
\hline Tender joint count & -0.08 & 0.41 & 0.31 & 0.002 & 0.39 & $<0.001$ \\
\hline Swollen joint count & -0.17 & 0.09 & 0.39 & $<0.001$ & 0.44 & $<0.001$ \\
\hline ESR (mm/1st h) & -0.15 & 0.15 & 0.35 & $<0.001$ & 0.44 & $<0.001$ \\
\hline C-reactive protein (mg/l) & -0.16 & 0.11 & 0.33 & $<0.001$ & 0.34 & $<0.001$ \\
\hline Hemoglobin (g/dL) & 0.18 & 0.07 & -0.34 & $<0.001$ & -0.43 & $<0.001$ \\
\hline White blood cells $\left(\times 10^{3} / \mathrm{ul}^{3}\right)$ & -0.04 & 0.72 & 0.21 & 0.03 & 0.06 & 0.19 \\
\hline Neutrophils $\left(\times 10^{3} / \mathrm{ul}^{3}\right)$ & -0.04 & 0.68 & 0.52 & $<0.001$ & 0.39 & $<0.001$ \\
\hline$d N L R$ & -0.002 & 0.98 & - & - & 0.45 & $<0.001$ \\
\hline Platelets $\left(\times 10^{3} / \mathrm{ul}^{3}\right)$ & -0.06 & 0.56 & 0.25 & 0.01 & 0.31 & 0.002 \\
\hline Rheumatoid factor (IU/mL) & 0.03 & 0.74 & 0.17 & 0.08 & 0.07 & 0.48 \\
\hline Anti-CCP (IU/mL) & 0.06 & 0.56 & -0.004 & 0.97 & 0.03 & 0.79 \\
\hline Albumin (g/dL) & - & - & -0.002 & 0.98 & -0.59 & $<0.001$ \\
\hline Albumin-dNLR score & -0.59 & $<0.001$ & 0.45 & $<0.001$ & - & - \\
\hline DAS28-ESR & -0.17 & 0.09 & 0.45 & $<0.001$ & 0.54 & $<0.001$ \\
\hline Greyscale & -0.09 & 0.37 & 0.35 & $<0.001$ & 0.42 & $<0.001$ \\
\hline Power Doppler & -0.17 & 0.09 & 0.46 & $<0.001$ & 0.43 & $<0.001$ \\
\hline Total 12 joints US score & -0.12 & 0.23 & 0.4 & $<0.001$ & 0.44 & $<0.001$ \\
\hline
\end{tabular}

ESR erythrocyte sedimentation rate, $d N L R$ derived neutrophil-to-lymphocyte ratio, Anti-CCP Anti-cyclic citrullinated peptide, DAS disease activity score, US ultrasound, NSAIDs nonsteroidal anti-inflammatory drugs. Bold values refers to significance at $p<0.05$. 
Table 3 Receiver operating characteristic (ROC) curve for the performance of dNLR, albumin-dNLR score, ESR, and CRP in predicting DAS28 and power Doppler score in rheumatoid arthritis patients

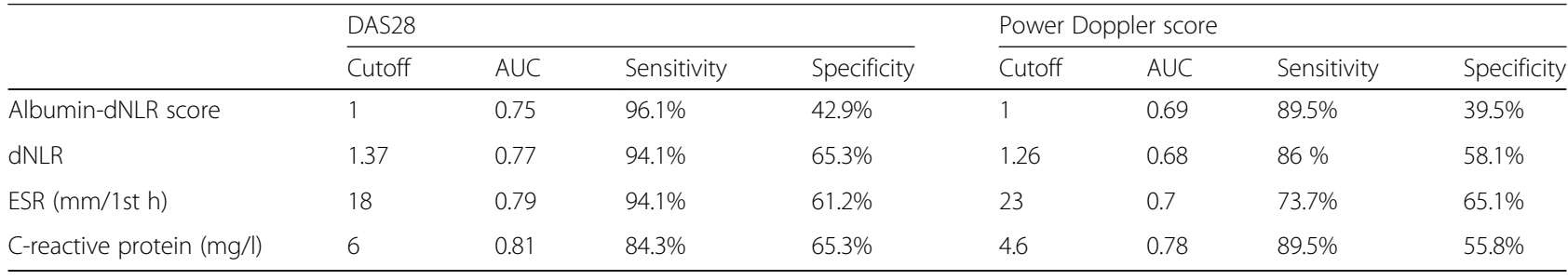

$E S R$ erythrocyte sedimentation rate, $d N L R$ derived neutrophil-to-lymphocyte ratio, DAS disease activity score, $A U C$ area under the curve

baseline data of RA patients and healthy controls were shown in Table 1. No significant difference regarding albumin-dNLR score was found between RA patients with cutaneous, pulmonary, and ocular involvement $(p=$ $0.48, p=0.45$, and $p=0.66$, respectively) compared to those without. Also, no significant difference $(p=0.11)$ regarding albumin-dNLR score was found between seropositive $(n=82)$ and seronegative $(n=18)$ RA patients.

Serum albumin was significantly decreased in RA patients with high activity $(n=17)$ in comparison with those in remission $(n=19, p=0.035)$ and moderate activity ( $n=34, p=0.02)$. Also, RA patients with high activity had significantly increased dNLR more than those with inactive disease $(p<0.001)$ and low disease activity $(n=30, p=0.004)$ (Fig. 2).
In RA patients, albumin-dNLR score had a significant correlation with DAS28 $(p<0.001)$, ESR $(p<0.001)$, CRP $(p<0.001)$, platelet count $(p=0.002)$, GS $(p<$ $0.001)$, PD $(p<0.001)$, and total ultrasound score $(p<$ $0.001)$. The correlations between albumin, dNLR, and albumin-dNLR score with different characteristics of RA patients were presented in Table 2.

Table 3 showed the sensitivity, specificity, and best cutoff point of albumin-dNLR score, dNLR, ESR, and CRP in prediction of DAS28-ESR and PD score in RA patients calculated using the ROC curve analysis.

Logistic regression analysis for predictors of DAS28 in RA patients was shown in Table 4: tender joint count $(p$ $=0.001)$, ESR $(p=0.012)$, and albumin-dNLR score $(p=$

Table 4 Logistic regression analysis for predictors of disease activity using DAS28 among rheumatoid arthritis patients

\begin{tabular}{|c|c|c|c|c|c|c|}
\hline \multirow[t]{2}{*}{ Variable } & \multicolumn{3}{|c|}{ Univariate } & \multicolumn{3}{|c|}{ Multivariate } \\
\hline & $\overline{\mathrm{OR}}$ & $95 \% \mathrm{Cl}$ & $P$ & OR & $95 \% \mathrm{Cl}$ & $P$ \\
\hline Age (years) & 1.01 & 0.97 to 1.05 & 0.52 & - & - & - \\
\hline Gender (male:female) & 0.50 & 0.2 to 1.22 & 0.13 & - & - & - \\
\hline BMI $\left(\mathrm{kg} / \mathrm{m}^{2}\right)$ & 1.09 & 0.95 to 1.26 & 0.20 & - & - & - \\
\hline Tender joint count & 3.04 & 1.88 to 4.92 & $<0.001$ & 6.79 & 2.14 to 21.54 & 0.001 \\
\hline Swollen joint count & 12.51 & 4.47 to 35.04 & $<0.001$ & - & - & - \\
\hline ESR (mm/1st h) & 1.04 & 1.01 to 1.07 & 0.01 & 1.10 & 1.02 to 1.19 & 0.012 \\
\hline C-reactive protein (mg/l) & 1.16 & 1.07 to 1.26 & $<0.001$ & - & - & - \\
\hline Hemoglobin (g/dL) & 0.67 & 0.52 to 0.88 & 0.003 & - & - & - \\
\hline white blood cells $\left(\times 10^{3} /\left.\mathrm{u}\right|^{3}\right)$ & 1.02 & 0.83 to 1.24 & 0.88 & - & - & - \\
\hline Neutrophils $\left(\times 10^{3} / \mathrm{ul}^{3}\right)$ & 1.34 & 0.99 to 1.81 & 0.06 & - & - & - \\
\hline$d N L R$ & 6.91 & 2.44 to 19.55 & $<0.001$ & - & - & - \\
\hline Platelets $\left(\times 10^{3} /\left.u\right|^{3}\right)$ & 1.01 & 1.00 to 1.01 & 0.004 & - & - & - \\
\hline Rheumatoid factor (IU/MI) & 1.00 & 0.99 to 1.01 & 0.41 & - & - & - \\
\hline Anti-CCP (IU/mL) & 1.00 & 1.00 to 1.005 & 0.57 & - & - & - \\
\hline Albumin (g/dL) & 0.82 & 0.38 to 1.76 & 0.61 & - & - & - \\
\hline Albumin-dNLR score & 5.92 & 2.62 to 13.38 & $<0.001$ & 27.62 & 1.86 to 408.45 & 0.016 \\
\hline Grey scale & 3.26 & 1.87 to 5.68 & $<0.001$ & - & - & - \\
\hline Power doppler & 10.8 & 3.87 to 30.14 & $<0.001$ & - & - & - \\
\hline Total 12 joints US score & 2.59 & 1.65 to 4.08 & $<0.001$ & - & - & - \\
\hline
\end{tabular}

OR odd ratio, 95\% Cl 95\% confidence interval, ESR erythrocyte sedimentation rate, $d N L R$ derived neutrophil-to-lymphocyte ratio, Anti-CCP Anti-cyclic citrullinated peptide, DAS disease activity score, US ultrasound. Bold values refers to significance at $p<0.05$. 
0.016) were significant predictors of DAS28 in multivariate regression analysis.

\section{Discussion}

Rheumatoid arthritis is defined by its symmetrical destructive inflammation of the synovial tissue that leads to irreversible joint damage if not properly treated [18]. Close monitoring of RA disease activity is necessary to achieve treat-to-target strategy with the aim of reduction of articular damage and functional disability [19]. Exploration of new biomarkers in RA continues to be an interesting issue as there is a growing need of biomarkers that can help in diagnosis, disease monitoring, identification of treatment response, and predicting prognosis [20].

Our RA patients had increased dNLR compared to controls that correlated with acute phase reactants, DAS28, clinical, and ultrasonographic parameters of activity. Other investigators found similar results and suggested that dNLR could be a helpful cheap marker to monitor disease activity [12, 21,22] and has the ability to predict remission [23] and treatment response [24] in RA patients.

Furthermore, Zengin et al. [25] reported a significant difference in dNLR between active early RA patients and those in remission, and they concluded that dNLR can help the diagnosis of early RA.

Neutrophils are one of the key players of innate immunity, while lymphocytes are the cells that are engaged in adaptive immunity. Innate immunity activation has been proposed to be the initial event in RA pathogenesis which is followed later by synthesis of neoepitopes and auto-antigens through carbamylation or citrullination mechanisms. These antigens are loaded on antigenpresenting cells (APCs) which present them to T lymphocytes of central lymphoid organs. T lymphocytes can stimulate B lymphocytes to produce pathogenic autoantibodies or it can migrate directly to inflamed joints [26, 27].

There is an increased production and activation of neutrophils in response to increased proinflammatory cytokines and mediators associated with chronic systemic inflammatory conditions [28], while Wood et al. [29]suggested that chronic inflammation leads to suppression of lymphocyte synthesis as a result of impairment in apoptosis regulatory mechanisms. This can explain the increase of dNLR in RA patient.

Moreover, neutrophils can contribute in the RA pathophysiology through many mechanisms as production of many immune mediators [30] and reactive oxygen species [31]. Also, synovial fluid neutrophils express receptor activator of nuclear factor-kB ligand (RANKL) which regulates the process of bone remodeling mediated by osteoclasts [32].
Albumin constitutes about $60 \%$ of the total concentration of plasma proteins [8] and is considered one of the negative acute phase reactants as its level decreases in response to inflammatory reactions. Many mechanisms were suggested to explain the negative correlation between albumin and systemic inflammation such as extravascular albumin loss due to increased vascular permeability, hemodilution, and suppressed hepatic production by inflammatory cytokines. Also, albumin levels can be affected by the status of malnutrition found in 24.7 to $50 \%$ RA patients [33,34]. The decreased albumin levels in our RA patients were confirmed by many other studies in the literature $[6,35]$.

Combination of albumin concentration with dNLR in one index (albumin-dNLR score) was speculated to be a valuable biomarker to reflect inflammatory status in gastric cancer [36], pancreatic cancer [37], and RA [14]. We observed a higher albumin-dNLR score in our RA patients compared to healthy subjects. Furthermore, it correlated well with DAS28 and ultrasonographic GS and PD synovitis scores. Also, we reported a significant correlation between albumin-dNLR score and platelet count that is linked to propagation of inflammation and disease activity in RA patients [38, 39].

Yet, no significant difference was found regarding albumin-dNLR score between seropositive RA patients and those who were seronegative. Moreover, albumindNLR score did not correlate with RF or anti-CCP autoantibodies.

To best of our knowledge, only one retrospective study reported the association of albumin-dNLR score with disease activity parameters among their RA patients [14]. Moreover, they suggested that it can enhance the efficacy of RA diagnosis. However, this marker should be interpreted with caution in conditions associated with hypoalbuminemia especially in those with hepatic or renal disorders.

A strength point of our study lies in its prospective nature. Also, disease activity in our RA patients was evaluated using DAS28 and MSUS. Our work had some limitations as all our patients were recruited from one center that might not represent the whole population spectrum. Also, most of our patients were receiving medication that can affect the significance of our results, and there is a need to conduct a follow-up study to examine the effect of different therapeutic agents on albumin-dNLR score in comparison with other inflammatory markers to determine which of these activity markers is suitable for each patient and to test the prognostic value of this marker. Study of this biological marker is also recommended to be done in different rheumatological diseases. 


\section{Conclusions}

Our study proved that albumin-dNLR score is increased in RA patients than in healthy subjects. Also, its significant correlation with DAS28, acute phase reactants, and ultrasonographic synovitis scores implies that it can be used as an inexpensive, available, and valuable biomarker to monitor RA disease activity during the routine followup visits without extra burden on the patient.

\section{Abbreviations \\ RA: Rheumatoid arthritis; dNLR: Derived neutrophil-to-lymphocyte ratio; MSUS: Musculoskeletal ultrasound; DAS: Disease activity score; RF: Rheumatoid factor; Anti-CCP: Anti-cyclic citrullinated peptide; CRP: C- reactive protein; ESR: Eythrocyte sedimentation rate; $\mathrm{CBC}$ : Complete blood count; GS: Greyscale; PD: Power Doppler; SD: Standard deviation; IQR: Interquartile range}

\section{Acknowledgements}

Not applicable.

\section{Authors ${ }^{-}$contributions}

All authors participated in study design. AH collected the data, and the initial draft of the manuscript was written by SG and WH. Musculoskeletal ultrasound examination was performed by $\mathrm{WH}$. all authors have read and approved the manuscript.

\section{Funding}

Not applicable.

\section{Availability of data and materials}

Available from corresponding author on reasonable request.

\section{Ethics approval and consent to participate}

The study was approved by the ethics committee of Benha faculty of medicine (Number: MS 6-9) on 18 September 2019, and a written consent was provided by all study participants.

\section{Consent for publication}

Not applicable.

\section{Competing interests}

Not applicable.

Received: 26 March 2020 Accepted: 18 May 2020

Published online: 31 August 2020

\section{References}

1. Aletaha D, Smolen JS (2018) Diagnosis and management of rheumatoid arthritis: a review. JAMA 320(13):1360-1372

2. -Gaujoux-Viala C, Gossec L, Cantagrel A, Dougados M, Fautrel B, Mariette X et al; French Society for Rheumatology (2014) Recommendations of the French Society for Rheumatology for managing rheumatoid arthritis. Joint Bone Spine 81: 287-97.

3. Takeuchi T (2018) Biomarkers as a treatment guide in rheumatoid arthritis. Clin Immunol 186:59-62

4. Giacomelli R, Afeltra A, Alunno A, Bartoloni-Bocci E, Berardicurti O, Bombardieri $\mathrm{M}$ et al (2019) Guidelines for biomarkers in autoimmune rheumatic diseases - evidence based analysis. Autoimmun Rev 18(1):93-106

5. Filippucci E, Cipolletta E, Mashadi Mirza R, Carotti M, Giovagnoni A, Salaffi F et al (2019) Ultrasound imaging in rheumatoid arthritis. Radiol Med 124(11): 1087-1100

6. Ben-Hadj-Mohamed M, Khelil S, Ben Dbibis M, Khlifi L, Chahed H, Ferchichi S et al (2017) Hepatic proteins and inflammatory markers in rheumatoid arthritis patients. Iran J Public Health 46(8):1071-1078

7. Arif Z, Arfat MY, Ahmad J, Zaman A, Islam SN, Khan MA (2015) Relevance of nitroxidation of albumin in rheumatoid arthritis: a biochemical and clinical study. J Clin Cell Immunol 6(2):1000324

8. Neto NSR, Freire de Carvalho J (2009) The use of inflammatory laboratory tests in rheumatology. Bras J Rheumatol 49(4):413-430
9. Martins EC, Silveira LDF, Viegas K, Beck AD, Fioravantti Júnior G, Cremonese RV et al (2019) Neutrophil-lymphocyte ratio in the early diagnosis of sepsis in an intensive care unit: a case-control study. Rev Bras Ter Intensiva 31(1):64-70

10. Proctor MJ, McMillan DC, Morrison DS, Fletcher CD, Horgan PG, Clarke SJ (2012) A derived neutrophil to lymphocyte ratio predicts survival in patients with cancer. Br J Cancer 107(4):695-699

11. D'Amico E, Zanghì A, Romano A, Sciandra M, Palumbo GAM, Patti F (2019) The neutrophil-to-lymphocyte ratio is related to disease activity in relapsing remitting multiple sclerosis. Cells 8(10). pii: E1114.

12. Erre GL, Paliogiannis P, Castagna F, Mangoni AA, Carru C, Passiu G et al (2019) Meta-analysis of neutrophil-to-lymphocyte and platelet-tolymphocyte ratio in rheumatoid arthritis. Eur J Clin Invest 49(1):e13037

13. Ahn SS, Jung SM, Song JJ, Park YB, Lee SW (2018) Neutrophil to lymphocyte ratio at diagnosis can estimate vasculitis activity and poor prognosis in patients with ANCA-associated vasculitis: a retrospective study. BMC Nephrol 31;19(1):187.

14. Chen S, Ying H, Du J, Zhu X, Shi J, Zhang $Y$ et al (2019) The association between albumin-dNLR score and disease activity in patients with rheumatoid arthritis. J Clin Lab Anal. 33(3):e22695

15. Aletaha D, Neogi T, Silman AJ, Funovits J, Felson DT, Bingham CO 3rd et al (2010) Rheumatoid arthritis classification criteria an American College of Rheumatology/European League Against Rheumatism. Arthritis Rheum 62(9):2569-2581

16. Prevoo ML, van't HMA, Kuper $H H$, van Leeuwen MA, van de Putte $L B$, van Riel PL (1995) Modified disease activity scores that include twenty-eightjoint counts. Development and validation in a prospective longitudinal study of patients with rheumatoid arthritis. Arthritis Rheum 38:44-8.

17. Naredo E, Rodríguez M, Campos C, Rodríguez-Heredia JM, Medina JA, Giner E et al (2008) Validity, reproducibility, and responsiveness of a twelve-joint simplified power Doppler ultrasonographic assessment of joint inflammation in rheumatoid arthritis. Arthritis Rheum 59:515-522

18. Littlejohn EA, Monrad SU (2018) Early diagnosis and treatment of rheumatoid arthritis. Prim Care 45(2):237-255

19. Bergstra SA, Allaart CF (2018) What is the optimal target for treat-to-target strategies in rheumatoid arthritis? Curr Opin Rheumatol 30(3):282-287

20. Gavrilă Bl, Ciofu C, Stoica V (2016) Biomarkers in rheumatoid arthritis, what is new? J Med Life 9(2):144-148

21. Fawzy RM, Said EA, Mansour Al (2017) Association of neutrophil to lymphocyte ratio with disease activity indices and musculoskeletal ultrasound findings in recent onset rheumatoid arthritis patients. Egypt Rheumatol 39(4):203-206

22. Chandrashekara S, Mukhtar Ahmad M, Renuka P, Anupama KR, Renuka K (2017) Characterization of neutrophil-to-lymphocyte ratio as a measure of inflammation in rheumatoid arthritis. Int J Rheum Dis 20(10):1457-1467

23. Chandrashekara S, Rajendran A, Jaganath AB, Krishnamurthy R (2015) Neutrophil-lymphocyte ratio, pain perception, and disease activity score may serve as important predictive markers for sustained remission in rheumatoid arthritis. Reumatismo 67(3):109-115

24. Ghang B, Kwon O, Hong S, Lee CK, Yoo B, Kim YG (2017) Neutrophil-tolymphocyte ratio is a reliable marker of treatment response in rheumatoid arthritis patients during tocilizumab therapy. Mod Rheumatol 27(3):405-410

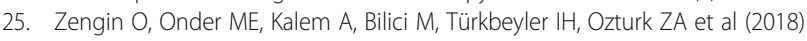
New inflammatory markers in early rheumatoid arthritis. Z Rheumatol. 77(2): 144-150

26. Guo Q, Wang Y, Xu D, Nossent J, Nathan J, Pavlos NJ, Xu J (2018) Rheumatoid arthritis: pathological mechanisms and modern pharmacologic therapies. Bone Res 6:15

27. Marston B, Palanichamy A, Anolik JH (2010) B cells in the pathogenesis and treatment of rheumatoid arthritis. Curr Opin Rheumatol. 2010 May; 22(3):307-315.

28. Noack M, Miossec P (2017) Selected cytokine pathways in rheumatoid arthritis. Semin Immunopathol. 39(4):365-383

29. Wood KL, Twigg HL 3rd, Doseff Al (2009) Dysregulation of CD8+ lymphocyte apoptosis, chronic disease, and immune regulation. Frontiers in bioscience (Landmark edition) 14:3771-3781. https://doi.org/10.2741/3487

30. Cecchi I, Arias de la Rosa I, Menegatti E, Roccatello D, Collantes-Estevez E, Lopez-Pedrera C et al (2018) Novel key players in rheumatoid arthritis. Current and future therapeutic targets. Autoimmun Rev 17(11):1138-1149

31. Bylund J, MacDonald KL, Brown KL, Mydel P, Collins LV, Hancock RE et al (2007) Enhanced inflammatory responses of chronic granulomatous disease 
leukocytes involve ROS independent activation of NF-kappa B. Eur J Immunol 37:1087-1096

32. Poubelle PE, Chakravarti A, Fernandes MJ, Doiron K, Marceau AA (2007) Differential expression of RANK, RANK-L, and osteoprotegerin by synovial fluid neutrophils from patients with rheumatoid arthritis and by healthy human blood neutrophils. Arthritis Res Ther 9:R25

33. Fukuda W, Yamazaki T, Akaogi T, Hayashi H, Kusakabe T, Tsubouchi Y et al (2005) Malnutrition and disease progression in patients with rheumatoid arthritis. Mod Rheumatol 15(2):104-107

34. Munro R, Capell H (1997) Prevalence of low body mass in rheumatoid arthritis: association with the acute phase response. Ann Rheum Dis 56:326-329

35. Tsuji H, Hashimoto M, Harada T, Tanaka M, Ito H, Murakami K (2019) Persistent anemia and hypoalbuminemia in rheumatoid arthritis patients with low serum triiodothyronine level [published online ahead of print, 2019 Aug 8]. Mod Rheumatol 2019:1-8

36. Sun X, Wang J, Liu J, Chen S, Liu X (2016) Albumin concentrations plus neutrophil lymphocyte ratios for predicting overall survival after curative resection for gastric cancer. Onco Targets Ther 9:4661-4669

37. Liu JX, Li A, Zhou LY, Liu XF, Wei ZH, Wang XZ et al (2018) Significance of combined preoperative serum Alb and dNLR for diagnosis of pancreatic cancer. Future Oncol 14(3):229-239

38. Olumuyiwa-Akeredolu $\mathrm{OO}$, Pretorius E (2015) Platelet and red blood cell interactions and their role in rheumatoid arthritis. Rheumatol Int 35:1955-1964

39. Gasparyan AY, Stavropoulos-Kalinoglou A, Mikhailidis DP, Toms TE, Douglas KMJ, Kitas GD (2011) Platelet function in rheumatoid arthritis: arthritic and cardiovascular implications. Rheumatol Int 31:153-164

\section{Publisher's Note}

Springer Nature remains neutral with regard to jurisdictional claims in published maps and institutional affiliations.

\section{Submit your manuscript to a SpringerOpen ${ }^{\circ}$ journal and benefit from:}

- Convenient online submission

- Rigorous peer review

- Open access: articles freely available online

- High visibility within the field

- Retaining the copyright to your article

Submit your next manuscript at $\boldsymbol{\nabla}$ springeropen.com 